\title{
Role of the supplementary motor area in the automatic activation of motor plans in de novo Parkinson's disease patients
}

\author{
Kevin D’Ostilio a,*, Benjamin Deville ${ }^{\mathrm{a}}$, Julien Cremers ${ }^{\mathrm{a}, \mathrm{b}}$, Julien Grandjean ${ }^{\mathrm{c}}$, \\ Eva Skawiniak $^{\mathrm{b}}$, Valérie Delvaux ${ }^{\mathrm{b}}$, Gaëtan Garraux ${ }^{\mathrm{a}, \mathrm{b}}$ \\ a MoVeRe Group, Cyclotron Research Center, University of Liege, Liege, Belgium \\ b Department of Neurology, University Hospital Center, Sart Tilman, Liege, Belgium \\ c Cyclotron Research Center, University of Liege, Liege, Belgium
}

\section{A R T I C L E I N F O}

\section{Article history:}

Received 18 December 2012

Received in revised form 3 April 2013

Accepted 15 April 2013

Available online 1 May 2013

\section{Keywords:}

Subliminal

Parkinson's disease

Priming

Reaction time

Neuroimaging

Supplementary motor area

\begin{abstract}
A B S T R A C T
The role of the basal ganglia-cortical motor loop in automatic and unconscious motor processes is poorly understood. Here, we used event-related functional magnetic resonance imaging in 11 de novo Parkinson's disease patients as they performed a visuomotor masked priming task. The stronger subliminal priming effect for the non-dominant side of motor symptoms than for the dominant side was paralleled by stronger supplementary motor area proper activity in response to lateralized visual stimuli presented below the threshold of awareness. This novel result supports the prediction that this area is involved in the automatic activation of motor plans as a function of striatal dopamine levels.
\end{abstract}

(C) 2013 Elsevier Ireland Ltd and the Japan Neuroscience Society. All rights reserved.
The pathological hallmark of Parkinson's disease (PD) is a progressive loss of neurons in the lateral ventral tiers of the substantia nigra pars compacta (Fearnley and Lees, 1991), leading to a decrease of dopaminergic nigrostriatal terminals that is typically more pronounced in the posterior aspects of the striatum in the hemisphere contralateral to the most clinically affected body side (Kish et al., 1988). Since the posterior putamen is the main input structure of the motor loop in the model proposed by Alexander et al. (1990), the loss of striatal dopaminergic terminals is expected to have remote influences on other components of the motor loop during voluntary movements. According to this model, the major problem in motor slowness is a deficiency in the activation of cortical areas involved in the motor loop, notably the more posterior part of the medial premotor cortex, the supplementary motor area proper (SMA), which is considered to be a key structure of the cortico-basal ganglia motor loop (Nachev et al., 2008; Aron et al., 2009). This prediction has been supported by many experimental results in PD patients. A failure to activate the SMA during the execution of upper limb movements is a consistent observation in PD patients studied in the off state as compared with controls (Jenkins et al., 1992; Playford et al., 1992; Jahanshahi et al., 1995). Apomorphine, a non-selective D1/D2

\footnotetext{
* Corresponding author. Tel.: +32 436654 75; fax: +32 43662946

E-mail address: Kevin.dostilio@ulg.ac.be (K. D’Ostilio).
}

agonist (Albin et al., 1989; DeLong, 1990; Jenkins et al., 1992; Rascol et al., 1992), fetal mesencephalic dopaminergic transplants into the striatum (Piccini et al., 2000), pallidotomy (Grafton et al., 1995; Samuel et al., 1997), pallidal and subthalamic electric stimulation (Limousin et al., 1997), all increase the level of SMA activity along with resolution of akinesia (i.e. delayed movement initiation).

In healthy subjects, we and others have shown that SMA activity changes can be elicited by the presentation of visual stimuli if these have been associated with a specific motor response regardless of whether (i) stimuli are presented below or above the level of awareness and (ii) the corresponding motor response is executed or not (Boy et al., 2010; D’Ostilio and Garraux, 2011; D'Ostilio et al., 2012). More precisely, we provided functional magnetic resonance imaging (fMRI) evidence suggesting that SMA activity is involved in the processing of motor plans automatically elicited by unconsciously perceived visual stimuli, even if the corresponding plan is not executed (D'Ostilio and Garraux, 2011). In patients, a focal lesion of the posterior part of the SMA has been associated with a deficit in the automatic and unconscious inhibition of movements (Sumner et al., 2007).

Here, we hypothesized that this SMA activity pattern is dependent on striatal dopamine levels. This was tested using a within-subject design in 11 de novo, drug-naïve, PD patients under the assumption that striatal dopamine deficiency is asymmetrical, i.e. less pronounced in the motor loop concerned with the control 
of the less clinically affected hand (i.e. non-dominant side of motor symptoms) than that concerned with the control of the most clinically affected hand (i.e. dominant side of motor symptoms). We predicted stronger SMA activity following the presentation of visual stimuli associated with lateralized motor responses involving the former than those involving the latter. We monitored SMA activity changes using rapid event-related fMRI as PD patients performed a subliminal visuo-motor task, as previously reported (D'Ostilio and Garraux, 2011). Participants were asked to respond (response trials) or to not respond (no-response trials) to consciously perceived visual stimuli that were preceded by a masked prime left- or rightpointing arrow presented below the threshold of awareness. We used a short interstimulus interval (ISI) (i.e. no delay between the mask and the target) in order to study the positive compatibility effect (PCE) that reflects the automatic activation of movements. We did not examine the negative compatibility effect (NCE) reflecting an inhibition process at longer ISIs (Sumner et al., 2007). To minimize any bias in motor performance between left and right hand responses, we restricted fMRI data analysis to trials that did not require any motor response.

Eleven de novo drug naïve PD patients (3 women/8 men) participated in the fMRI experiment. De novo patients were preferred as it is known that asymmetry is more pronounced early on in the disease (Riederer and Sian-Hülsmann, 2012). Age ranged from 59 to 80 years, with a mean \pm SD of $68 \pm 7$ years. All were right handed and had normal or corrected-to-normal vision and hearing. Global motor impairment was assessed using the motor part (part III) of the UPDRS (Fahn et al., 1987) and the Hoehn and Yahr scale (Hoehn and Yahr, 1967; Goetz et al., 2004). The group mean score on these scales was $15 \pm 6$ and $1.4 \pm 0.5$, respectively (Table 1 ). As expected, composite UPDRS III scores (sum of UPDRSIII scores from item 22: rigidity + item 23: finger taps + item 24: hand movements + item 25: pronation-supination movements of hands) showed higher impairment on the dominant side (median $=8$ ) as compared with the non-dominant side ( median $=2$ ) of motor symptoms (Wilcoxon test: $Z=2.93, p=0.003$ ). All subjects provided informed written consent in this study that was approved by the ethics committee of the University of Liège.

The visuo-motor task during fMRI was similar to that previously reported (D'Ostilio and Garraux, 2011) (Fig. 1). Briefly, each trial started with a fixation dot displayed on the center of the screen for a duration that was pseudo-randomly jittered between 1500 and $3000 \mathrm{~ms}$ across trials. This was followed by a blank screen, a prime stimulus and a mask stimulus along with target stimulus sequentially displayed for $300 \mathrm{~ms}, 33 \mathrm{~ms}$, and $100 \mathrm{~ms}$, respectively. The prime stimulus was either a double arrow pointing to the left or the right or a plus sign. The mask stimulus consisted in
30 randomly oriented lines covering the area of the prime stimulus display. A new mask was constructed on each trial. The target stimulus appeared at the same time, on both sides of the mask. It consisted of either two double arrows or two " 0 " signs. The former prompted participants to make a rapid button press with their left or right index finger in accordance with the arrow direction while the latter indicated no motor response trials. Thus, the prime-target relationship defined 6 main experimental conditions for a total of 288 trials randomly presented within and across subjects: compatible, incompatible, neutral, left primed no-response, right primed no-response, and neutral no-response.

As in many previous studies (Schlaghecken et al., 2003; Seiss and Praamstra, 2004), the magnitude of the prime-induced motor response facilitation was formally assessed by comparing behavioral performance between compatible and incompatible conditions (i.e. response trials). Reaction time data analysis showed a PCE for the non-dominant side of motor symptoms [PCE: $19 \mathrm{~ms}$; $t(10)=2.54, p=0.03$ ] but not for the dominant side [PCE $=3 \mathrm{~ms}$; $t(10)=0.14, p>0.05]$. In addition, as expected, the patients made more errors when the no-response conditions were preceded by an arrow prime (error rate for prime arrow no-response trials: $6.8 \%>$ neutral no-response trials: $3.6 \% ; p=0.045$ ).

Functional MRI time series were acquired on a $3 \mathrm{~T}$ head-only scanner (Magnetom Allegra, Siemens Medical Solutions, Erlangen, Germany) operated with the standard transmit-receive quadrature head coil. Multislice T2*-weighted functional images were acquired with a gradient-echo echo-planar imaging sequence using axial slice orientation and covering most of the brain (20 slices, FoV $=220 \mathrm{~mm} \times 220 \mathrm{~mm}$, voxel size $3.4 \mathrm{~mm} \times 3.4 \mathrm{~mm} \times 5 \mathrm{~mm}, 25 \%$ interslice gap, matrix size $64 \times 64 \times 20, \mathrm{TR}=1170 \mathrm{~ms}, \mathrm{TE}=30 \mathrm{~ms}$, $\mathrm{FA}=90^{\circ}$ ). For each session, the first eight volumes acquired before the first trial onset were discarded to allow for T1 saturation effects. Head movement was minimized by restraining the subject's head using a vacuum cushion. Stimuli were displayed on a screen positioned at the rear of the scanner, which the subject could comfortably see through a mirror mounted on the standard head coil. For anatomical reference, a high-resolution T1-weighted image was acquired for each subject $\left(3 \mathrm{D}\right.$ MDEFT, $\mathrm{TR}=7.92 \mathrm{~ms}, \mathrm{TE}=2.4 \mathrm{~ms}, \mathrm{TI}=910 \mathrm{~ms}, \mathrm{FA}=15^{\circ}$, FoV $=256 \mathrm{~mm} \times 224 \mathrm{~mm} \times 176 \mathrm{~mm}, 1 \mathrm{~mm}$ isotropic spatial resolution).

Data were preprocessed and analyzed using SPM8 (Wellcome Department of Imaging Neuroscience, http://www.fil.ion.ucl.ac.uk/spm) implemented in MATLAB 7.4.0 (Mathworks Inc., Sherbom, MA). Images of each individual subject were first corrected for slice timing and realigned (motion corrected). The mean EPI image was spatially coregistered to the

Table 1

Demographic and clinical patients' data.

\begin{tabular}{|c|c|c|c|c|c|c|c|c|}
\hline Patients & Age (years) & Gender & Global RT & DS & NDS score & DS score & UPDRS part III ${ }^{\mathrm{a}}$ & Hoehn and Yahr scale ${ }^{b}$ \\
\hline 1 & 59 & M & 470.75 & Right & 2 & 8 & 11 & 1 \\
\hline 2 & 66 & M & 479.09 & Left & 4 & 10 & 23 & 2 \\
\hline 3 & 80 & $\mathrm{~F}$ & 686.75 & Left & 3 & 9 & 23 & 2 \\
\hline 4 & 66 & M & 483.43 & Right & 1 & 7 & 10 & 2 \\
\hline 5 & 72 & $\mathrm{~F}$ & 542.50 & Left & 1 & 3 & 9 & 1 \\
\hline 6 & 59 & M & 502.29 & Right & 3 & 9 & 19 & 1 \\
\hline 7 & 65 & M & 397.88 & Left & 4 & 12 & 22 & 2 \\
\hline 8 & 63 & M & 552.03 & Right & 4 & 7 & 16 & 1 \\
\hline 9 & 75 & M & 611.72 & Left & 1 & 3 & 4 & 1 \\
\hline 10 & 78 & $\mathrm{~F}$ & 961.87 & Right & 2 & 9 & 17 & 1.5 \\
\hline 11 & 70 & M & 476.30 & Right & 1 & 7 & 15 & 1.5 \\
\hline
\end{tabular}

DS = dominant side of motor symptoms; NDS = non-dominant side of motor symptoms.

a UPDRS: minimum score $=0$, maximum score $=108$.

b Hoehn and Yahr scale: stage 0: no signs of disease; stage 1.0: unilateral disease; stage 1.5: unilateral and axial involvement; stage 2.0: bilateral involvement without

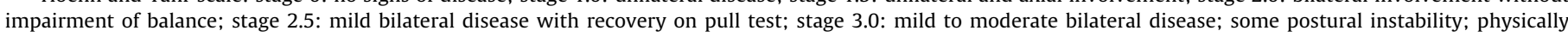
independent; stage 4.0: severe disability; still able to walk or stand unassisted; stage 5.0: wheelchair bound or bedridden unless aided. 


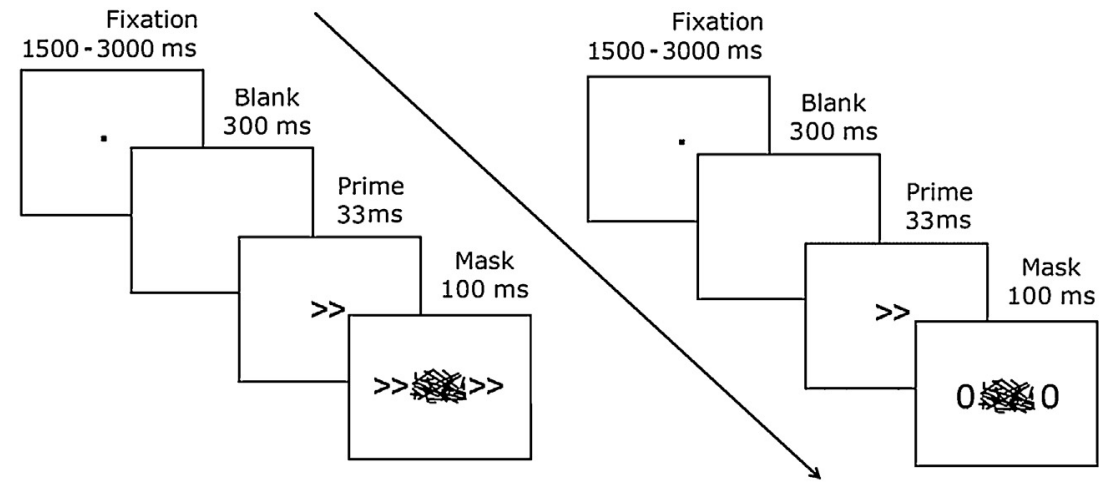

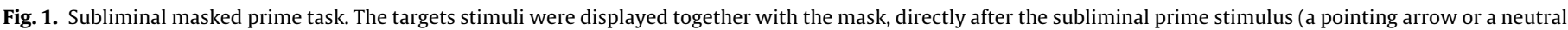
stimulus), and were either composed of double pointing arrows (=response trials) or double "0" signs (=no-response trials).

anatomical MRI image and coregistration parameters were applied to the realigned BOLD time series. Individual anatomical MRIs were spatially normalized into MNI space (Montreal Neurological Institute, http://www.bic.mni.mcgill.ca) and the normalization parameters were subsequently applied to the individually coregistered BOLD times series, which was then resliced to a voxel size of $2 \mathrm{~mm} \times 2 \mathrm{~mm} \times 2 \mathrm{~mm}$, and smoothed using an $6 \mathrm{~mm}$ FWHM Gaussian kernel. In first level analyses, the six experimental conditions were modeled separately. Each event was time-locked to the target stimulus of each trial and convolved with a canonical hemodynamic response function and its time and dispersion derivatives. We used the generalized linear model to model the intensity level of each voxel as a linear combination, for each subject and event.

The neural correlates of the difference in the level of primeinduced activation of motor plans between the dominant and non-dominant side of motor symptoms was examined using noresponse trials. Since we postulated that the priming effect is asymmetrically affected, we contrasted prime-induced activation of the motor plan for the non-dominant and the dominant side of motor symptoms (Fig. 2). Contrast images from all participants were entered in a second-level random effect one-sample $t$-test analysis. By comparing the 11 contrast images related to the nondominant side (right or left) to those of the dominant side of motor symptoms (right or left), we expected a stronger bilateral activity in the SMA. Results are reported in this region at $p<0.005$, uncorrected with a 20 voxel extent threshold of activation. The predicted activations in the SMA were further tested using a spherical smallvolume correction (SVC) with a radius of $10 \mathrm{~mm}$ (cut-off value: 0.05 , family wise error [FWE] corrected), centered on the peak coordinates from our previous subliminal priming studies (right SMA, MNI: 8, -2, 62) (D'Ostilio and Garraux, 2011, 2012).

As expected, we found stronger bilateral SMA activity when the motor plan for the non-dominant side of motor symptoms was subliminally activated (i.e. when the prime arrow pointed to the same side as this hand) compared with that for the dominant side [left SMA-proper: $(-10,-6,58), Z=3.93$, $p$ (unc. $)=0.00004$; right SMA-proper: $(14,-12,58), Z=3.50$,
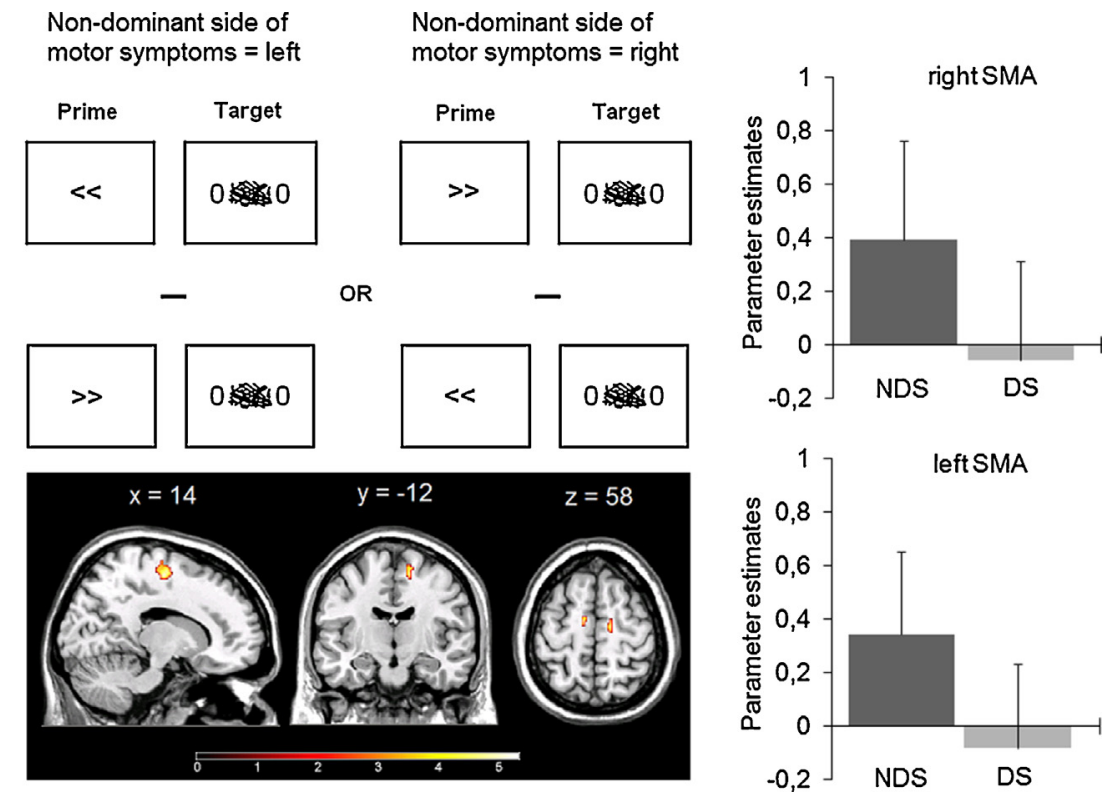

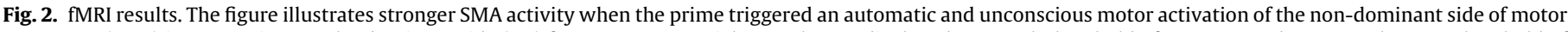

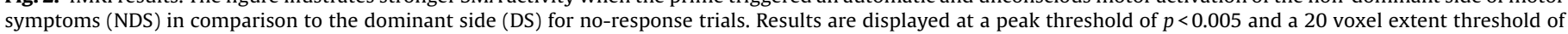
activation. 
$p($ unc. $)=0.0002, p($ FWE $)=0.04]$ (Fig. 1$)$. This differential SMA activity suggests disturbed prime-induced activation of motor plans for the dominant side as compared with the non-dominant side.

Additional fMRI analyses were performed on motor response trials: an ANOVA to test for differences in brain activity changes associated with compatible and incompatible trials and a correlation analysis between the magnitude of the BOLD signal and the magnitude of the compatibility effect. The former revealed a stronger activation of the SMA for the compatible condition (i.e. compatible > incompatible and neutral) [right SMA-proper: $(12,-4$, 52), $Z=3.44, p$ (unc.) $=0.0003$ ], while in the latter, we did not find any correlation between SMA BOLD activity and the compatibility effect.

After the fMRI session, three patients in the experimental group performed a prime identification task consisting in 180 trials. Results showed that they correctly identified the subliminal 33 msstimulus in only $33 \%$ of all trials. The identification performance was very low because patients did not respond to some trials despite clear instructions. Results obtained in a separate group of 15 PD patients confirmed that a $33 \mathrm{~ms}$-prime is unlikely to be consciously perceived by participants. This was formally assessed using an identification task containing 60 trials. The task display was exactly the same as in the fMRI experiment but participants were asked to guess the direction of the prime arrow stimuli presented before the mask. The percentage of correct responses was calculated and compared to chance levels. Participants identified the prime in $47 \%$ of all trials (i.e. at chance levels), supporting the statement that the prime stimuli were not consciously perceived in our task.

The aim of this study was to examine SMA activity related to the automatic and unconscious motor activation process in early stages PD patients while administering a subliminal visuomotor priming task (Eimer and Schlaghecken, 1998). fMRI data analysis revealed stronger activations in the posterior part of the SMA, bilaterally, when the prime stimulus triggered a motor response with the non-dominant side as compared with the dominant side of motor symptoms. This result is not confounded by difference in motor performance between the former and the latter since the fMRI data analysis was restricted to trials in which no motor response was required. This extends previous findings on impaired-movement related SMA activity in PD to unconscious and automatic motor processes. This result corroborates previous findings suggesting that this region participates in automatic activation of motor plans unconsciously elicited by visual stimuli (Grezes and Decety, 2002; D'Ostilio and Garraux, 2011). Our data do not allow us to investigate the relative contribution of other components of the cortico-basalcortical motor loop. Since the medial frontal cortex hypoactivation may account for the patients' difficulties in initiating movements (Jenkins et al., 1992; Playford et al., 1992) and because sensorimotor integration at the level of the motor preparation is impaired in PD patients (Abbruzzese and Berardelli, 2003), we propose that lateralized motor deficits of automatic and unconscious motor activation might partially explain the early motor symptoms of the disease such as the slowness in selecting the appropriate motor response.

\section{Authors' contributions}

Kevin D'Ostilio was implied in conception, organization and execution of the research project, design and execution of the statistical analysis, as well as in drafting the manuscript. Benjamin Deville, Julien Cremers, Julien Grandjean, Eva Skawiniak, and Valérie Delvaux were implied in the execution of the research project and gave revision of the manuscript. Gaëtan Garraux was implied in conception, organization and execution of the research project, design of the statistical analysis, and gave critical revision of the manuscript.

\section{Conflict of interest}

Nothing to report.

\section{Acknowledgements}

This work was supported by FRS-FNRS (Grant 1.5.047.06). The authors would like to thank Ms Luci Crook for English editing.

\section{References}

Abbruzzese, G., Berardelli, A., 2003. Sensorimotor integration in movement disorders. Mov. Disord. 18, 231-240.

Albin, R.L., Young, A.B., Penney, J.B., 1989. The functional anatomy of basal ganglia disorders. Trends Neurosci. 12, 366-375.

Alexander, G.E., Crutcher, M.D., DeLong, M.R., 1990. Basal ganglia-thalamocortica circuits: parallel substrates for motor, oculomotor, "prefrontal" and "limbic" functions. Progr. Brain Res. 85, 119-146.

Aron, A.R., Wise, S.P., Poldrack, R.A., 2009. Cognition: basal ganglia role. In: Squire, L.R.(Ed.), Encyclopedia of Neuroscience. Academic Press, Oxford, pp. 1069-1077.

Boy, F., Husain, M., Singh, K.D., Sumner, P., 2010. Supplementary motor area activations in unconscious inhibition of voluntary action. Exp. Brain Res. 206, $441-448$.

D’Ostilio, K., Collette, F., Phillips, C., Garraux, G., 2012. Evidence for a role of a corticosubcortical network for automatic and unconscious motor inhibition of manual responses. PLoS ONE 7, e48007.

D’Ostilio, K., Garraux, G., 2011. Automatic stimulus-induced medial premotor cortex activation without perception or action. PLoS ONE 6, e16613.

D’Ostilio, K., Garraux, G., 2012. Dissociation between unconscious motor response facilitation and conflict in medial frontal areas. Eur. J. Neurosci. 35, 332-340.

DeLong, M.R., 1990. Primate models of movement disorders of basal ganglia origin. Trends Neurosci. 13, 281-285.

Eimer, M., Schlaghecken, F., 1998. Effects of masked stimuli on motor activation: behavioral and electrophysiological evidence. J. Exp. Psychol. Hum. Percept. Perform. 24, 1737-1747.

Fahn, S., Elton, R., Committee, U.D., 1987. Unified Parkinson's disease rating sclae. In: Fahn, S., Marsden, C.D., Calne, D.B., Goldstein, M. (Eds.), Recent Development in Parkinson's Disease. Macmillan, Florham Park, NJ, pp. 153-164.

Fearnley, J.M., Lees, A.J., 1991. Ageing and Parkinson's disease: substantia nigra regional selectivity. Brain 114 (5), 2283-2301.

Goetz, C.G., Poewe, W., Rascol, O., Sampaio, C., Stebbins, G.T., Counsell, C., Giladi, N., Holloway, R.G., Moore, C.G., Wenning, G.K., Yahr, M.D., Seidl, L., 2004. Movement disorder society task force report on the Hoehn and Yahr staging scale: status and recommendations. Mov. Disord. 19, 1020-1028.

Grafton, S.T., Waters, C., Sutton, J., Lew, M.F., Couldwell, W., 1995. Pallidotomy increases activity of motor association cortex in Parkinson's disease: a positron emission tomographic study. Ann. Neurol. 37, 776-783.

Grezes, J., Decety, J., 2002. Does visual perception of object afford action? Evidence from a neuroimaging study. Neuropsychologia 40, 212-222.

Hoehn, M.M., Yahr, M.D., 1967. Parkinsonism: onset, progression and mortality. Neurology 17, 427-442.

Jahanshahi, M., Jenkins, I.H., Brown, R.G., Marsden, C.D., Passingham, R.E., Brooks D.J., 1995. Self-initiated versus externally triggered movements. I. An investigation using measurement of regional cerebral blood flow with PET and movement-related potentials in normal and Parkinson's disease subjects. Brain $118,913-933$.

Jenkins, I.H., Fernandez, W., Playford, E.D., Lees, A.J., Frackowiak, R.S., Passingham, R.E., Brooks, D.J., 1992. Impaired activation of the supplementary motor area in Parkinson's disease is reversed when akinesia is treated with apomorphine Ann. Neurol. 32, 749-757.

Kish, S.J., Shannak, K., Hornykiewicz, O., 1988. Uneven pattern of dopamine loss in the striatum of patients with idiopathic Parkinson's disease. N. Engl. J. Med. 318, $876-880$.

Limousin, P., Greene, J., Pollak, P., Rothwell, J., Benabid, A.L., Frackowiak, R., 1997 Changes in cerebral activity pattern due to subthalamic nucleus or internal pallidum stimulation in Parkinson's disease. Ann. Neurol. 42, 283-291.

Nachev, P., Kennard, C., Husain, M., 2008. Functional role of the supplementary and pre-supplementary motor areas. Nat. Rev. Neurosci. 9, 856-869.

Piccini, P., Lindvall, O., Bjorklund, A., Brundin, P., Hagell, P., Ceravolo, R., Oertel, W. Quinn, N., Samuel, M., Rehncrona, S., Widner, H., Brooks, D.J., 2000. Delayed recovery of movement-related cortical function in Parkinson's disease after striatal dopaminergic grafts. Ann. Neurol. 48, 689-695.

Playford, E.D., Jenkins, I.H., Passingham, R.E., Nutt, J., Frackowiak, R.S., Brooks, D.J., 1992. Impaired mesial frontal and putamen activation in Parkinson's disease: a positron emission tomography study. Ann. Neurol. 32, 151-161.

Rascol, O., Sabatini, U., Chollet, F., Celsis, P., Montastruc, J.L., Marc-Vergnes, J.P., Rascol, A., 1992. Supplementary and primary sensory motor area activity in 
Parkinson's disease. Regional cerebral blood flow changes during finger movements and effects of apomorphine. Arch. Neurol. 49, 144-148.

Riederer, P., Sian-Hülsmann, J., 2012. The significance of neuronal lateralisation in Parkinson's disease. J. Neural Transm. 119, 953-962.

Samuel, M., Ceballos-Baumann, A.O., Turjanski, N., Boecker, H., Gorospe, A., Linazasoro, G., Holmes, A.P., DeLong, M.R., Vitek, J.L., Thomas, D.G., Quinn, N.P., Obeso, J.A., Brooks, D.J., 1997. Pallidotomy in Parkinson's disease increases supplementary motor area and prefrontal activation during performance of volitional movements an H2(15)O PET study. Brain 120 (Pt 8), 1301-1313.
Schlaghecken, F., Munchau, A., Bloem, B.R., Rothwell, J., Eimer, M., 2003. Slow frequency repetitive transcranial magnetic stimulation affects reaction times, but not priming effects, in a masked prime task. Clin. Neurophysiol. 114, 1272-1277.

Seiss, E., Praamstra, P., 2004. The basal ganglia and inhibitory mechanisms in response selection: evidence from subliminal priming of motor responses in Parkinson's disease. Brain 127, 330-339.

Sumner, P., Nachev, P., Morris, P., Peters, A.M., Jackson, S.R., Kennard, C., Husain, M., 2007. Human medial frontal cortex mediates unconscious inhibition of voluntary action. Neuron 54, 697-711. 